Check for updates

Cite this: RSC Adv., 2017, 7, 21697

Received 25th February 2017

Accepted 3rd April 2017

DOI: $10.1039 / \mathrm{c} 7 \mathrm{ra02348 \textrm {k }}$

rsc.li/rsc-advances

\section{Synthesis, optical properties and residual strain effect of GaN nanowires generated via metal- assisted photochemical electroless etching}

\begin{abstract}
Adel Najar, (D) *a Muhammad Shafa ${ }^{a}$ and Dalaver Anjum ${ }^{b}$
Herein, we report on the studies of GaN nanowires (GaN NWs) prepared via a metal-assisted photochemical electroless etching method with Pt as the catalyst. It has been found that etching time greatly influences the growth of GaN NWs. The density and the length of nanowires increased with longer etching time, and excellent substrate coverage was observed. The average nanowire width and length are around $35 \mathrm{~nm}$ and $10 \mu \mathrm{m}$, respectively. Transmission electron microscopy (TEM) shows a single-crystalline wurtzite structure and is confirmed by X-ray measurements. The synthesis mechanism of GaN NWs using the metal-assisted photochemical electroless etching method was presented. Photoluminescence (PL) measurements of GaN NWs show red-shift PL peaks compared to the as-grown sample associated with the relaxation of compressive stress. Furthermore, a shift of the $E_{2}$ peak to the lower frequency in the Raman spectra for the samples etched for a longer time confirms such a stress relaxation. Based on Raman measurements, the compressive stress $\sigma_{\mathrm{xx}}$ and the residual strain $\varepsilon_{\mathrm{xx}}$ were evaluated to be 0.23 GPa and $2.6 \times 10^{-4}$, respectively. GaN NW synthesis using a low cost method might be used for the fabrication of power optoelectronic devices and gas sensors.
\end{abstract}

\section{Introduction}

Semiconductor nanowires (NWs) are attractive building blocks for realizing highly efficient nano-scale devices. These nanostructures have a large surface-to-volume ratio and can also exhibit a reduced dimensionality, ${ }^{1}$ which have much potential for optoelectronic device fabrication. This quasi-one-dimensional morphology offers the possibility to investigate surface-mediated phenomena and quantum confinement effects, which strongly affect the physical properties of NW semiconductor materials. In addition, compared to quantum dots, NWs are easier to contact and handle, and they can be used as active devices, as well as interconnects or waveguides. ${ }^{2,3}$ Furthermore, their small cross-sections can accommodate much larger lattice mismatch and thermal expansion differences compared to planar layers because strain is released at the free NW sidewalls. ${ }^{4}$ Hence, NWs offer a larger design freedom for the heteroepitaxy of highly lattice-mismatched materials, which is crucial for the monolithic integration of high performance III-V semiconductors with Si technology. The design and fabrication of several different types of devices have already been demonstrated for applications in electronics, computing, photonics, sensing, and biology.,5 Single-crystalline 1D semiconductor nanostructures have received an enormous amount of

${ }^{a}$ Department of Physics, College of Science, United Arab Emirates University, Al Ain 15505, United Arab Emirates.E-mail: adel.najar@uaeu.ac.ae

${ }^{b}$ Imaging and Characterization Lab, King Abdullah University of Science and Technology (KAUST), 23599-6900, Thuwal, Kingdom of Saudi Arabia attention as building blocks for future optoelectronic devices. ${ }^{6}$ Gallium nitride is a robust wideband-gap semiconductor with a high melting point, high carrier mobility, and a high electrical breakdown field. It is a prime candidate for use in future high-performance, high power optoelectronic devices. ${ }^{7-9}$ Singlecrystalline GaN NWs and nanotubes are promising for realizing photonic and biological nanodevices such as blue-light emitting diodes (LEDs), short-wavelength ultraviolet nanolasers, ${ }^{10,11}$ and nanofluidic biochemical sensors.

Virtually, to date, all reported synthetic schemes for GaNbased nanowires have employed either laser ablation, ${ }^{12}$ chemical vapor transport, ${ }^{9,11,13,14}$ or hybrid vapor epitaxy. ${ }^{15}$ Most of these processes use Ga metal as the high-temperature vapor source. Metals such as $\mathrm{Ni}, \mathrm{Fe}$, and $\mathrm{Au}$ have been used as initiators for vapor-liquid-solid (VLS) nanowire growth, ${ }^{12}$ although self-catalytic VLS or a direct vapor-solid process can also generate nanowires in this system. ${ }^{16} \mathrm{~A}$ recently developed photoetching system for n-type $\mathrm{GaN}$, in $\mathrm{KOH}$ solution containing the strong oxidizing agent potassium peroxydisulphate $\left(\mathrm{K}_{2} \mathrm{~S}_{2} \mathrm{O}_{8}\right)$, was studied by Weyher et al. ${ }^{17,18}$ The development of the metal-assisted electroless etching to synthesise silicon nanowires was well established during the last few years. ${ }^{19,20}$ However, a few reports explored the synthesis of GaN NWs using metal-assisted electroless etching, but the etching mechanism was not well established. ${ }^{21}$ Furthermore, the optical and mechanical properties of the GaN NWs, generated via the metal-assisted photochemical electroless method, are not well developed. 
In this study, we report on the fabrication of GaN NWs, using a metal-assisted photochemical electroless method. The morphological structures of GaN NWs prepared under different etching times were investigated. The etching mechanism of GaN NWs was developed. The optical properties, the compressive stress $\sigma_{\mathrm{xx}}$, and the residual strain $\varepsilon_{\mathrm{xx}}$ were investigated using PL and Raman measurements.

\section{Results and discussion}

The morphology of GaN NWs was studied as a function of the etching time of 90, 180, 240, and $300 \mathrm{~min}$. Fig. 1 shows the SEM images for different etching times. The sample etched for 90 min in Fig. 1(a) is composed of porous GaN with a few NWs. The length of the nanowires is less than $2 \mu \mathrm{m}$. As long as the etching time increases to $180 \mathrm{~min}$ in Fig. 1(b), the surface is wholly covered with GaN NWs. A high density of GaN NWs has been observed on the samples etched for $240 \mathrm{~min}$ and $300 \mathrm{~min}$, as shown in Fig. 1(c) and (d). High resolution SEM images (inset) show that the average diameter of nanowires is about $35 \mathrm{~nm}$ and about 1-13 $\mu \mathrm{m}$ in length. Furthermore, the cross section image in Fig. 1(e) corresponding to 180 min etching time shows that the shorter nanowires are vertical and supported by the underlying nanoporous GaN structures.

Fig. 2 shows the high-resolution TEM images, and the corresponding calculated fast Fourier transform (FFT) patterns (inset image) of individual GaN nanowires matches with the [0001] diffraction pattern. This pattern is single crystalline with symmetric diffraction spots showing the wurtzite structure of GaN NWs. Moreover, the interval of the closest inter-planar distance was measured to be $0.25 \mathrm{~nm}$, which corresponds to that of the crystal plane ( $\left.\begin{array}{lll}1 & 0 & 0\end{array}\right)$ of GaN. ${ }^{22,23}$ The morphology of the GaN NWs synthesized using metal-assisted photochemical electroless etching was different than that of the NWs prepared with the aid of Au-Pd as a vapor-solid-liquid (VLS) catalyst.

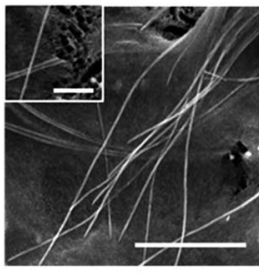

(a)

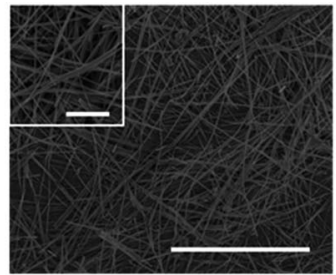

(d)

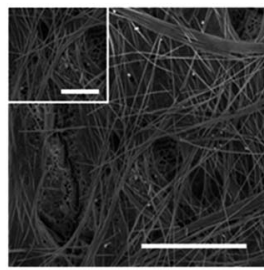

(b)

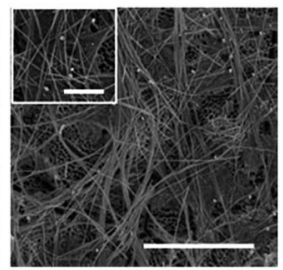

(c)

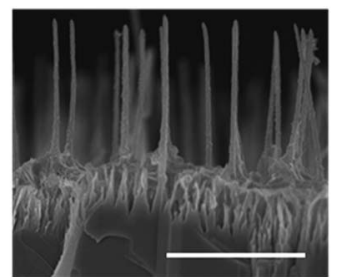

(e)

Fig. 1 SEM images for GaN NW samples and HRSEM in the inset for different etching times of (a) $90 \mathrm{~min}$, (b) $180 \mathrm{~min}$, (c) $240 \mathrm{~min}$, and (d) $300 \mathrm{~min}$. The scale bar is $1 \mu \mathrm{m}$ and $500 \mathrm{~nm}$ in the inset. (e) Crosssection image for $180 \mathrm{~min}$ etching time. Scale bar $500 \mathrm{~nm}$.

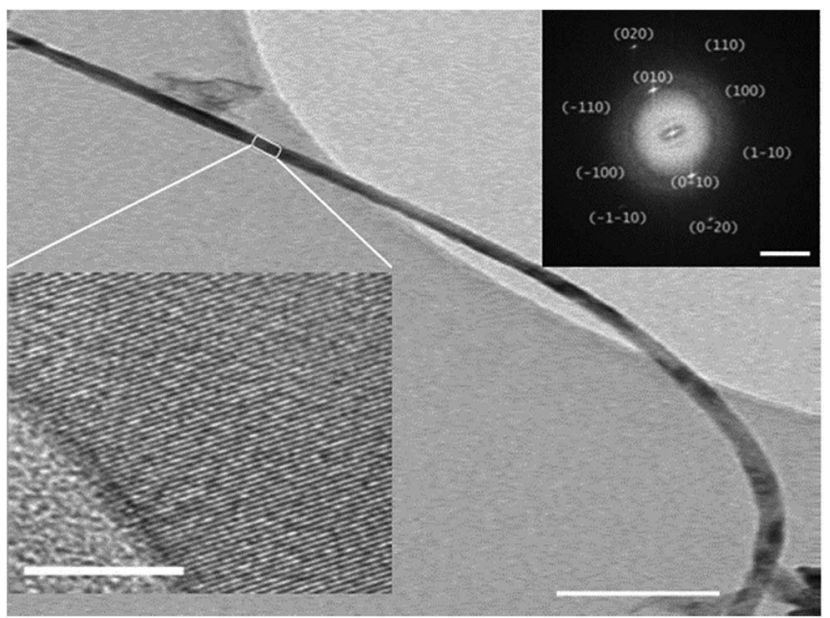

Fig. 2 TEM image of an individual NW, scale bar $100 \mathrm{~nm}$. Inset: FFT image with scale bar of $5 \mathrm{~nm}^{-1}$ and HRTEM with scale bar of $5 \mathrm{~nm}$.

Typical VLS-grown GaN nanowires exhibited triangular crosssections, and each of these nanowires was straight, smooth and tipped with a catalyst particle, a hallmark of the VLS process. ${ }^{16}$ However, GaN NWs synthesized using a metalassisted photochemical electroless etching method are simple, fast and less expensive compared to other complicated methods: MOCVD system or VLS growth. ${ }^{16}$

To confirm the TEM observations, X-ray diffraction measurement was recorded for the samples etched for $300 \mathrm{~min}$, and the results are shown in Fig. 3. The peaks on the spectrum can be indexed to the wurtzite GaN (JCPDS card no. 898624) with lattice constants of $a=0.3186 \mathrm{~nm}$ and $c=0.5178 \mathrm{~nm}$, and the diffraction peaks are located at $2 \theta=32.3^{\circ}, 34.5^{\circ}, 36.7^{\circ}$ and $57.8^{\circ}$ corresponding to (100), (002), (101) and (110) planes.

A schematic of the synthesis of GaN NWs via metal-assisted photochemical electroless etching is presented in Fig. 4. The proposed GaN NW etching mechanism has three steps. First, photo-generated electron-hole pairs $(\mathrm{e}-\mathrm{h})$ are generated at the GaN-electrolyte interface when exposed to ultraviolet light in the

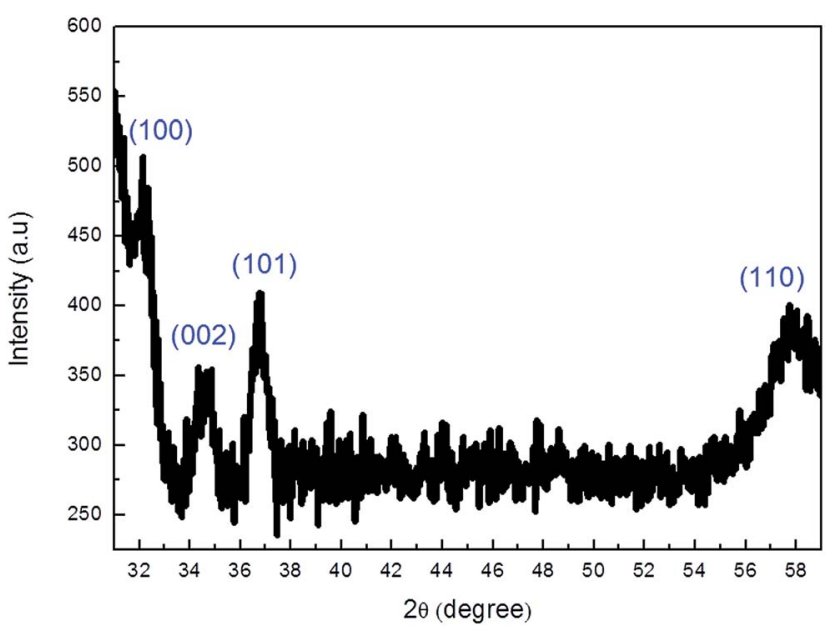

Fig. 3 X-ray diffraction pattern of wurtzite GaN NWs. 
a)

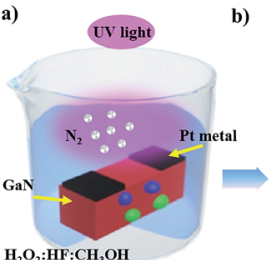

b)

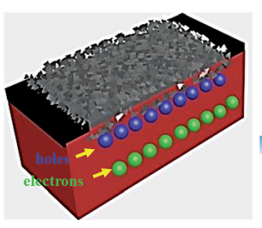

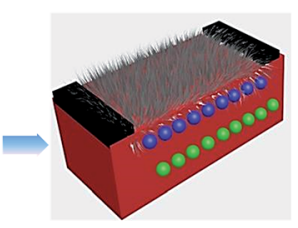

Fig. 4 Etching mechanism of GaN NWs. (a) Reaction of the GaN surface with $\mathrm{H}_{2} \mathrm{O}_{2}$ : $\mathrm{HF}: \mathrm{CH}_{3} \mathrm{OH}$ solution under UV light and generation of electron-hole pairs, (b) synthesis of porous GaN for short etching times, and (c) synthesis of GaN NWs for longer etching times.

presence of $\left(\mathrm{H}_{2} \mathrm{O}_{2}: \mathrm{HF}: \mathrm{CH}_{3} \mathrm{OH}\right)$ as the etching medium, as shown in Fig. 4(a). Due to the band bending at the interface of the GaN substrate-electrolyte, the photo-generated holes support the anode reaction at the surface of $\mathrm{GaN}$ for the oxidation reaction, while electrons diffuse into bulk GaN. In Fig. 4(b), the holes oxidize the surface layer to form $\mathrm{Ga}_{2} \mathrm{O}_{3}$ with the evolution of $\mathrm{N}_{2}$ gas, as depicted in eqn (a), and play the role of an anode. ${ }^{24}$

$$
2 \mathrm{GaN}+6 \mathrm{~h}^{+}+3 \mathrm{H}_{2} \mathrm{O} \rightarrow \mathrm{Ga}_{2} \mathrm{O}_{3}+6 \mathrm{H}^{+}+\mathrm{N}_{2}
$$

At platinum, the reduction reaction of $\mathrm{H}_{2} \mathrm{O}_{2}$ through eqn (b) takes place as the cathode to generate water. ${ }^{24}$

$$
\mathrm{H}_{2} \mathrm{O}_{2}+2 \mathrm{H}^{+} \rightarrow 2 \mathrm{H}_{2} \mathrm{O}+2 \mathrm{~h}^{+}
$$

Then, the second step is the reaction of $\mathrm{HF}$ with $\mathrm{Ga}_{2} \mathrm{O}_{3}$. This reaction will be on the GaN crystal grain surface, on the surface dislocations and on the grain boundaries of GaN crystallites. ${ }^{25}$ The dissolution of the $\mathrm{Ga}_{2} \mathrm{O}_{3}$ oxide takes place to form $\mathrm{GaF}_{3}$, as depicted in eqn (c).

$$
\mathrm{Ga}_{2} \mathrm{O}_{3}+6 \mathrm{HF} \rightarrow 2 \mathrm{GaF}_{3}+3 \mathrm{H}_{2} \mathrm{O}
$$

Under oxygen poor conditions, the dissolution of $\mathrm{Ga}_{2} \mathrm{O}_{3}$ oxide in HF solution will enhance the dangling bonds and will be responsible for the positive charges in the oxide. ${ }^{26}$ The repulsion of the $\mathrm{H}^{+}$charge ions in the solution from the positive oxide surface will reduce the dissolution rate of $\mathrm{Ga}_{2} \mathrm{O}_{3}$ on the crystal grain surface through eqn (d).

$$
\mathrm{Ga}_{2} \mathrm{O}_{3}+6 \mathrm{H}^{+} \rightarrow 2 \mathrm{Ga}^{3+}+3 \mathrm{H}_{2} \mathrm{O}
$$

However, dislocated sites and defects are negatively charged, ${ }^{26,27}$ and the dissolution of $\mathrm{Ga}_{2} \mathrm{O}_{3}$ can be easily initiated at surface defect sites showing a much faster rate due to $\mathrm{HF}^{28}$ For short etching times, pores are produced on the surface of the GaN film, as shown in the SEM images in Fig. 4(b). GaN NWs are formed along with porous structures. The last step is for longer etching times, when pores will be etched along the vertical (0001) crystallographic direction in the GaN layer at the dislocation sites, leaving behind NW structures. Then, the GaN NWs will become longer and will collapse after a few microns.

The etching process depends on the presence of a surface charge region $(w)$ at the $\mathrm{n}-\mathrm{GaN}$-electrolyte interface, which arises due to the GaN surface Fermi level equilibrium with the electrochemical potential of the electrolyte, as shown in Fig. $5{ }^{29}$ This surface charge region is characterized by the presence of surface electrical fields, which cause an upward bending in the energy bands near the surface. The metal-assisted photochemical electroless etching of $\mathrm{n}-\mathrm{GaN}$ initiates when the incident UV photons excite electron-hole pairs. If the carriers are excited up to the hole diffusion length, away from the surface charge region, ${ }^{29}$ holes may diffuse to the surface charge region where they drift towards the interface under the effect of the surface electric fields, or they simply recombine. The photo-generated holes reach the GaN/electrolyte interface and are localized at the surface bonds, allowing the surface gallium atoms to get oxidized, forming gallium oxide $\left(\mathrm{Ga}_{2} \mathrm{O}_{3}\right)$, as depicted in eqn (a). ${ }^{30}$

The PL measurements shown in Fig. 6 were conducted on the samples etched at different times of $90,180,240$, and $300 \mathrm{~min}$. The emission peaks are predominated by the bound exciton $D_{\mathrm{x}}^{0}$ located at $3.425 \mathrm{eV}(362 \mathrm{~nm})$ for the as-grown sample, $3.419 \mathrm{eV}(362.6 \mathrm{~nm})$ for the sample etched for $90 \mathrm{~min}, 3.414 \mathrm{eV}$ $(363.2 \mathrm{~nm})$ for the sample etched for $180 \mathrm{~min}, 3.412 \mathrm{eV}(363.4$ $\mathrm{nm})$ for the sample etched for $240 \mathrm{~min}$, and $3.41 \mathrm{eV}(363.7 \mathrm{~nm})$ for the sample etched for $300 \mathrm{~min}$. The PL spectra of the etched samples show a second peak by a donor-acceptor pair (DAP) at around $3.35 \mathrm{eV}(370 \mathrm{~nm})$. Therefore, a red-shift is discerned compared with the bulk GaN. This red-shift was attributed to the relaxation of compressive stress in the GaN NWs. Furthermore, the full width at half-maximum (FWHM) of the GaN NWs is broader compared to that of the as-grown sample, and this increase of FWHM could be attributed to the wide size distribution of the nanowires. ${ }^{31,32}$

Time-resolved PL measurements on dispersed nanowires in ethanol prepared from the sample etched at $300 \mathrm{~min}$ are studied at room temperature, as shown in the inset in Fig. 6 . The PL decay was fitted using a single-exponential decay. The lifetime emission was equal to $10 \mathrm{~ns}$. The measured lifetime is longer than the lifetime measured on GaN NWs grown by catalyst-free molecular-beam epitaxy, which is equal to $2 \mathrm{~ns}$ at $275 \mathrm{~K}^{33}$

Temperature dependent photoluminescence spectra of GaN NWs etched at $300 \mathrm{~min}$ are shown in Fig. 7. The near-band-edge (NBE) emission is at $3.474 \mathrm{eV}$ at $78 \mathrm{~K}$. As the temperature

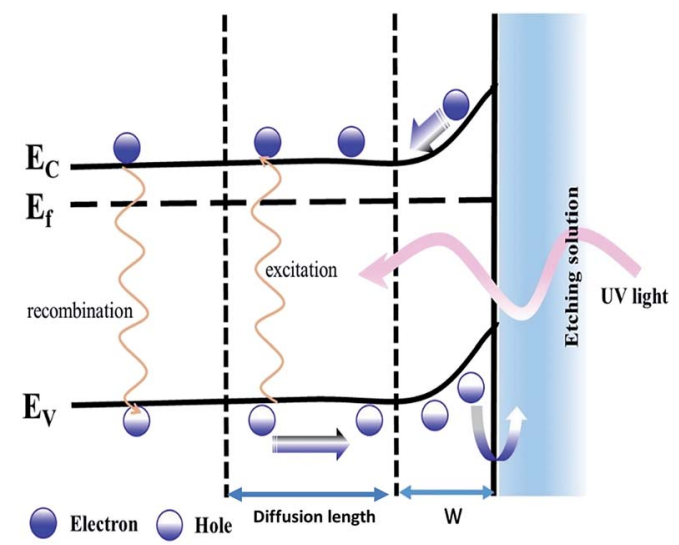

Fig. 5 Energy band diagram: between GaN film, electrolyte $\mathrm{H}_{2} \mathrm{O}_{2}: \mathrm{HF}: \mathrm{CH}_{3} \mathrm{OH}$. 


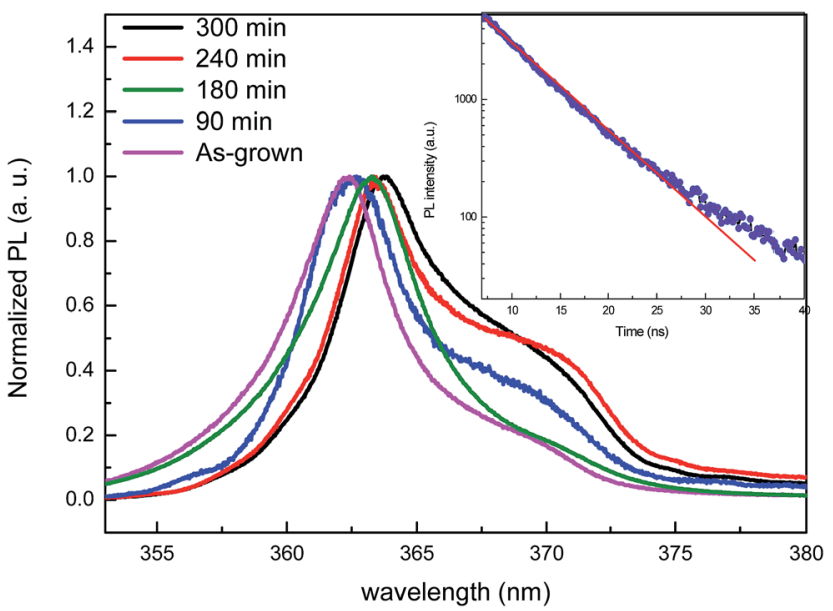

Fig. 6 PL spectra of as-grown GaN and GaN NW samples for different etching times: 90, 180, 240 and 300 min. Inset: PL decay of GaN NWs in ethanol from the sample etched for $300 \mathrm{~min}$.

increases, the peak position shifts to lower energy, and at $300 \mathrm{~K}$, the peak is around $3.41 \mathrm{eV}$, as shown in Fig. 7(a). Furthermore, the FWHM is increased with temperature. The crystalline property of these GaN NWs prepared by metal-assisted photochemical electroless etching is quite good compared to that of the external catalyst assisted GaN NWs grown using CVD. ${ }^{34}$ Using the Varshni formula, the energy versus temperature plot can be fitted by the below equation: ${ }^{35}$

$$
E_{\mathrm{g}}(T)=E_{\mathrm{g}}(0)-\left(\alpha T^{2} /(\beta+T)\right)
$$

where $E_{\mathrm{g}}(0)$ describes the energy gap at zero temperature; $\alpha$ and $\beta$ are known as Varshni's fitting parameters. Fig. 7(b) shows the Varshni fitting for the energy of the main peak at various temperatures for the sample etched for $300 \mathrm{~min}$ and covered with nanowires. The fitting parameters are $E_{\mathrm{g}}(0)=3.47 \mathrm{eV}, \alpha=$ $3.74 \times 10^{-3} \mathrm{eV} \mathrm{K}^{-1}$ and $\beta=462.6 \mathrm{~K}$. This value of $E_{\mathrm{g}}(0)$ is estimated to be $3.47 \mathrm{eV}$, and it agrees with the reported value for wurtzite GaN. ${ }^{36,37}$

Raman spectra for the as-grown sample and etched samples are shown in Fig. 8. The Raman spectra reveal that the $\mathrm{E}_{1}(\mathrm{TO})$ peak $\left(560.5 \mathrm{~cm}^{-1}\right)$ is visible for the etched samples. The $\mathrm{E}_{2}$ peak positions are located at $570.0 \mathrm{~cm}^{-1}$ for the as-grown sample, 569.4 $\mathrm{cm}^{-1}$ for the etching times of $90 \mathrm{~min}$ and $180 \mathrm{~min}$, and 569.0
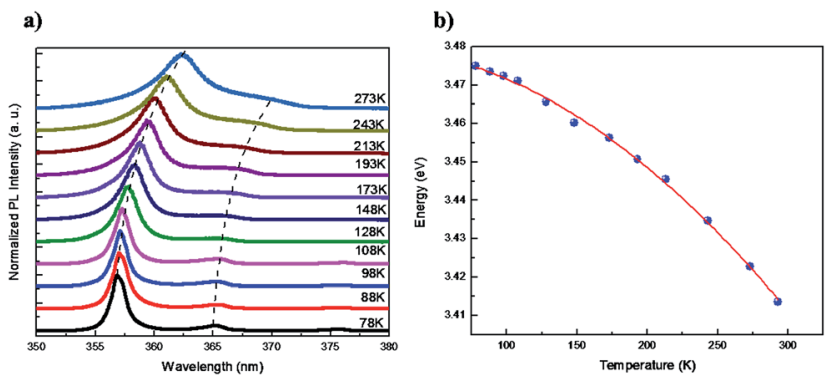

Fig. 7 (a) Temperature dependent PL spectra of GaN NWs and (b) Varshni fitting for the peak at $3.41 \mathrm{eV}$ with various temperatures.

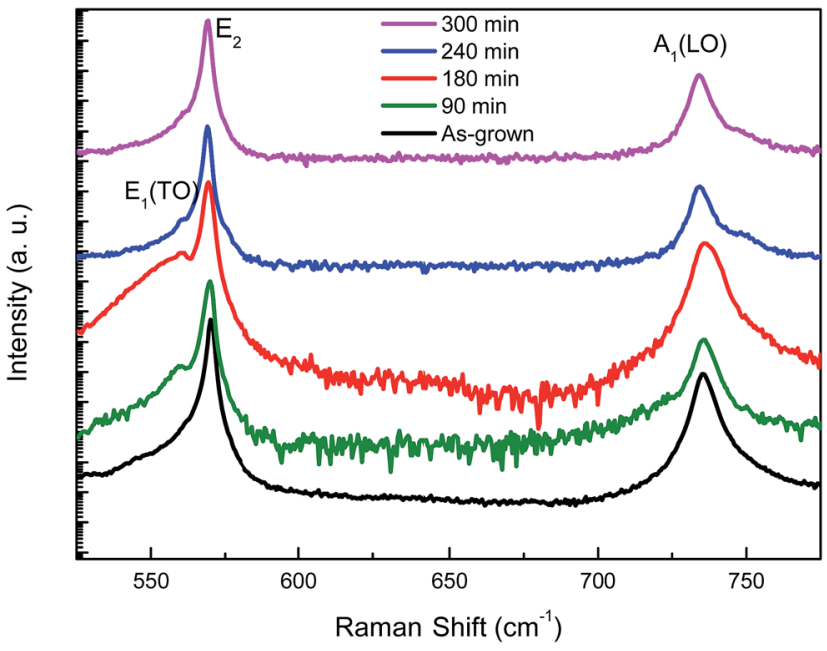

Fig. 8 Raman spectra of as-grown GaN, GaN NW samples for different etching times of $90 \mathrm{~min}, 180 \mathrm{~min}, 240 \mathrm{~min}$, and $300 \mathrm{~min}$.

$\mathrm{cm}^{-1}$ for samples etched for 240 and $300 \mathrm{~min}$. A shift of $\Delta \mathrm{E}_{2}$ (TO) $=1.0 \mathrm{~cm}^{-1}$ towards the lower wavenumber was measured for the samples at 240 and 300 min etching duration. The shift of $E_{2}$ to the lower frequency could be explained by the stress relaxation that takes place for the longer etching time. However, a new shoulder appears for the etched samples at $750.5 \mathrm{~cm}^{-1}$. This shoulder peak is attributed to a Froehlich mode due to the anisotropy etching. This observation has also been reported in columnar GaN prepared by illumination assisted anodic etching. ${ }^{38}$

The residual strain in GaN NWs can be evaluated based on these Raman measurements. The compressive stress $\left(\sigma_{\mathrm{xx}}\right)$ can be estimated by the expression $\Delta \mathrm{E}_{2}(\mathrm{TO})=K \sigma_{\mathrm{xx}} \mathrm{cm}^{-1} \mathrm{GPa}^{-1}$, where $\Delta \mathrm{E}_{2}(\mathrm{TO})$ is the shift in the wavenumber from GaN NWs and the as-grown $\mathrm{GaN}$, which is equal to $1.0 \mathrm{~cm}^{-1}$ for the samples etched for 240 and $300 \mathrm{~min}$, and $K$ is a proportionality factor equal to 4.2 $\mathrm{cm}^{-1} \mathrm{GPa}^{-1}$ for GaN. ${ }^{39,40}$ The calculated $\sigma_{\mathrm{xx}}$ in the GaN NWs equal $0.23 \mathrm{GPa}$. However, the compressive stress values in the literature for the as-grown and porous GaN prepared by the same method were evaluated to be $0.36 \mathrm{GPa}$ and $0.27 \mathrm{GPa}$, respectively. ${ }^{8}$ The compressive stress in the GaN NWs is lower than that in the asgrown sample due to the stress release. Furthermore, the residual strain, $\varepsilon_{\mathrm{xx}}$, in the GaN NWs can be obtained using the expression $\sigma_{\mathrm{xx}}=$ Mf. $\varepsilon_{\mathrm{xx}}$, where Mf is the biaxial modulus of the GaN substrate equal to $449.6 \mathrm{GPa}^{41}$ The residual strain, $\varepsilon_{\mathrm{xx}}$, in the nanowires is determined to be $2.6 \times 10^{-4}$. Hugues et al. shows that the in-plane strain in the GaN NWs prepared by Metal Organic Vapor Phase Epitaxy (MOVPE) is around $1.0 \times 10^{-3}$ and demonstrates that the strain decreases during the first 100$200 \mathrm{~nm}$ and is fully relaxed when the nanowire height reaches $300 \mathrm{~nm}^{42}$ Hence, residual strain measurements have been confirmed, which are one order of magnitude smaller due to the length (few microns) of our nanowires.

\section{Experimental}

The unintentionally doped n-type GaN film, used in this study, was grown on a $c$-axis (0001) sapphire substrate with a resistivity 
lower than $0.05 \Omega \mathrm{cm}$ and was purchased from Xiamen Powerway Advanced Material Co., LT. The thickness of the GaN film was about $30 \mu \mathrm{m}$, and the carrier concentration of the film was $3.4 \times 10^{17} \mathrm{~cm}^{-3}$. The GaN samples were cleaned by sonication in acetone, then followed by 2-propanol for $5 \mathrm{~min}$ in each solution. This was followed by immersing the sample in $\mathrm{HNO}_{3}$ at $65{ }^{\circ} \mathrm{C}$ for $15 \mathrm{~min}$. The samples were then rinsed in DI water and methanol. Two narrow strips of $10 \mathrm{~nm}$ thick Pt, separated by a few millimeters, were deposited on the GaN samples using a sputtering system. The samples were etched in the $\mathrm{H}_{2} \mathrm{O}_{2}$ : $\mathrm{HF}: \mathrm{CH}_{3} \mathrm{OH}(2: 1: 2)$ solution under UV illumination for different etching times (90, 180, 240, and $300 \mathrm{~min})$. After chemical etching, the samples were removed from the solution and rinsed with DI water. FEI's Magellan 400 FEG scanning electron microscopy (SEM) operating at $5 \mathrm{keV}$ beam energy and high-resolution transmission electron microscopy (HRTEM) were used to analyse the crystal structure, using the FEI's TitanG2 80-300 TEM. The X-ray measurements were performed on Bruker system (D8 Avance). The PL measurements were performed at room and low temperatures using the Jobin Yvon LabRAM HR 800 UV system. The PL decay was measured using a FLS920 fluorescence spectrometer from Edinburgh Instruments with an arc lamp as the excitation source (excitation wavelength at $325 \mathrm{~nm}$ ). A He Cd laser emitting at $325 \mathrm{~nm}$ and a diode-pumped solid-state (DPSS) laser emitting at $532 \mathrm{~nm}$ were used as excitation sources for PL and Raman measurements, respectively. The incident laser power for both measurements was set to $20 \mathrm{~mW}$.

\section{Conclusions}

In summary, fabrication of GaN NWs with nanoscale dimensions prepared by a metal-assisted photochemical electroless etching technique was investigated with different etching times. With longer etching times, GaN NWs were observed on the surface. The etching mechanism related to the synthesis of GaN NWs and the energy band diagram were presented. The PL measurements reveal that the peak positions of the GaN NW samples were red-shifted due to strain relaxation. The compressive stress and residual strain were determined to be $0.23 \mathrm{GPa}$ and $2.6 \times 10^{-4}$, respectively using Raman measurement.

\section{Acknowledgements}

The authors acknowledge the financial support from the UAE University under Stat-up project No. 31S214.

\section{References}

1 L. Cademartiri and G. A. Ozin, Adv. Mater., 2008, 21, 1013.

2 C. M. Lieber, MRS Bull., 2003, 28, 486.

3 P. J. Pauzauskie and P. Yang, Mater. Today, 2006, 9, 36.

4 F. Glas, Phys. Rev. B: Condens. Matter Mater. Phys., 2006, 74, 121302.

5 C. M. Lieber and Z. L. Wang, MRS Bull., 2007, 32, 99.
6 Y. Xia, P. Yang, Y. Sun, Y. Wu, B. Mayers, B. Gates, Y. Yin, F. Kim and H. Yan, Adv. Mater., 2003, 15, 353.

7 J. C. Johnson, H. Choi, K. P. Knutsen, R. D. Schaller, P. Yang and R. J. Saykally, Nat. Mater., 2002, 1, 106.

8 A. Najar, M. Gerland and M. Jouiad, J. Appl. Phys., 2012, 111, 093513.

9 J. Goldberger, R. He, Y. Zhang, S. Lee, H. Yan, H. J. Choi and P. Yang, Nature, 2003, 422, 599.

10 Y. Huang, X. Duan, Y. Cui and C. M. Lieber, Nano Lett., 2002, 2, 101.

11 H. Choi, J. Johnson, R. He, S. Lee, F. Kim, P. Pauzauskie, J. Goldberger, R. Saykally and P. J. Yang, J. Phys. Chem. B, 2003, 107, 8721.

12 X. Duan and C. M. Lieber, J. Am. Chem. Soc., 2000, 122, 188. 13 C. C. Chen, C. C. Yeh, C. H. Chen, M. Y. Yu, H. L. Liu, J. J. Wu, K. H. Chen, L. C. Chen, J. Y. Peng and Y. F. Chen, J. Am. Chem. Soc., 2001, 123, 2791.

14 H. W. Seo, S. Y. Bae, J. Park, H. N. Yang, K. S. Park and S. J. Kim, Chem. Phys., 2002, 116, 9492.

15 Z. Zhong, F. Qian, D. Wang and C. M. Lieber, Nano Lett., 2003, 3, 343.

16 D. Tham, C. Y. Nam and J. E. Fischer, Adv. Funct. Mater., 2006, 16, 1197.

17 J. L. Weyher, F. D. Tichelaar, D. H. Van Dorp, J. J. Kelly and A. Khachapuridze, J. Cryst. Growth, 2010, 312, 2607.

18 J. L. Weyher, J. Smalc-Koziorowsk, M. Bańkowsk, I. Dzięcielewski, Ł. Marona and P. Perlin, J. Cryst. Growth, 2015, 426, 153.

19 J. Charrier, A. Najar and P. Pirasteh, Appl. Surf. Sci., 2013, 283, 828-832.

20 Y. Qu, H. Zhou and X. Duan, Nanoscale, 2011, 3, 4060-4068.

21 X. Genga, B. K. Duan, D. A. Grismer, L. Zhao and P. W. Bohn, Electrochem. Commun., 2012, 19, 39-42.

22 Y. Yang, Y. Ling, G. Wang, X. Lu, Y. Tong and Y. Li, Nanoscale, 2013, 5, 1820.

23 H. Cheng, J. Li, D. Wu, Y. Li, Z. Wang, X. Wang and X. Zheng, J. Nanomater., 2015, 343541.

24 V. Dorogan, I. Tiginyanu, T. Vieru, R. Sturza, H. Hartnagel and C. H. Mutamba, Mold. J. Phys. Sci., 2002, N2, 156.

25 D. Chen, H. Xiao and J. Han, J. Appl. Phys., 2012, 112, 064303.

26 B. Senapati, S. K. Samanta, S. Maikap, L. K. Bera and C. K. Maiti, Appl. Phys. Lett., 2000, 77, 1840.

27 K. Leung, A. F. Wright and E. B. Stechel, Appl. Phys. Lett., 1999, 74, 2495.

28 J. B. Varley, J. B. Weber, A. Janotti and C. G. Van de Walle, Appl. Phys. Lett., 2010, 97, 42106.

29 K. Rajeshwar, in Encyclopedia of Electrochemistry, ed. A. J. Bard, M. Stratmann and S. Licht, Wiley-VCH, Germany, 2002, ch. 1, vol. 6 .

30 C. Youtsey, G. Bulman and I. Adesida, J. Electron. Mater., 1998, 27, 282.

31 A. Mahmood, N. M. Ahmed, Y. Yusof, Y. F. Kwong, C. L. Siang, H. R. Abd and Z. Hassan, Int. J. Electrochem. Sci., 2013, 8, 5801.

32 F. K. Yam, Z. Hassan, L. S. Chuah and Y. P. Ali, Appl. Surf. Sci., 2007, 253, 7429. 
33 J. B. Schlager, K. A. Bertness, P. T. Blanchard, L. H. Robins, A. Roshko and N. A. Sanford, J. Appl. Phys., 2008, 103, 124309.

34 Y. Jinkyoung, J. H. Young, S. J. An and G. C. Yi, Appl. Phys. Lett., 2006, 89, 043124.

35 Y. P. Varshni, Physica, 1967, 34, 149.

36 V. Bougrov, M. E. Levinshtein, S. L. Rumyantsev and A. Zubrilov, Properties of Advanced Semiconductor Materials: GaN, AIN, InN, BN, SiC, SiGe, John Wiley \& Sons, Inc., New York, 2001, pp. 1-30.

37 I. M. Tiginyanu, V. V. Ursaki, V. V. Zalamai, S. Langa, S. Hubbard, D. Pavlidis and H. Föll, Appl. Phys. Lett., 2003, 83, 8 .
38 I. M. Tiginyanu, A. Sarua, G. Irmer, J. Monecke, S. Hubbard, D. Pavlidis and V. Valiaev, Phys. Rev. B: Condens. Matter Mater. Phys., 2001, 64, 233317.

39 C. Kisielowski, J. Kruger, S. Ruvimov, T. Suski, J. W. Ager, E. Jones, Z. Liliental, M. Rubin and E. R. Weber, Phys. Rev. B: Condens. Matter Mater. Phys., 1996, 54, 17745.

40 D. G. Zhao, S. J. Xu, M. H. Xie, S. Y. Tong and H. Yang, Appl. Phys. Lett., 2003, 83, 677.

41 S. Chichibu, T. Azuhata, T. Sota and S. Nakamura, Appl. Phys. Lett., 1996, 69, 4188.

42 M. Hugues, P. A. Shields, F. Sacconi, M. Mexis, M. Auf der Maur, M. Cooke, M. Dineen, A. Di Carlo, D. W. E. Allsopp and J. Zúñiga-Pérez, J. Appl. Phys., 2013, 114, 084307. 